\title{
The prevalence of sexual activity, and sexual dysfunction and behaviours in postmenopausal woman in Poland
}

\author{
Kamila B. Czajkowska, Zbigniew Lew-Starowicz², Monika Szymańska \\ ${ }^{1}$ Institute of Sexology, Polish Sexological Society, Poland \\ ${ }^{2}$ Psychotherapy and Sexological Rehabilitation Department, The Józef Piłsudski University of Physical Education in Warsaw, Poland \\ ${ }^{3}$ Medical Sexology and Psychotherapy Department, Medical Centre for Postgraduate Education, Warsaw, Poland
}

\section{Abstract}

Introduction: Despite the aging of the population, there is limited data available about sexual life and behaviours among of postmenopausal and late postmenopausal women. Aim of the study was to assess the prevalence of sexual dysfunction, behaviours, and preferences in the Polish population in 2015.

Material and methods: This observational survey study involved 538 women, of whom 220 were over 50 years old. The main focus was on the differences and changes between older age groups, mainly 50-59 years and over 60 years.

Results: For $80.9 \%$ of the women above 50 years old, sex played at least a moderately important role in life. Sex was definitely important and very important for $40.45 \%$ of them. Most women over 50 years old (65.5\%) were sexually active. Regardless of age, the respondents were more likely to have sexual intercourse several times a month. Less than half of the women over 50 years old $(42.7 \%)$ realised their sexual fantasies. Women in the group of 50-59 years old statistically less often than younger women declared that the frequency of intercourse they had was too small. There was a statistical tendency showing that women up to 49 years old declared more sexual problems than older women. Women over 50 years old reported fewer problems in comparison to younger women, e.g. less often they claimed that sex is not pleasurable $(p=0.064)$.

Conclusions: The prevalence of sexual activity declines with age, yet a substantial number of woman engage in vaginal intercourse, oral sex, and masturbation even past the seventh decade of life.

Key words: female sexual dysfunction, postmenopause, sexual activity, sexual behaviours.

\section{Introduction}

Despite the aging of the population, there is limited data available about sexual life and behaviours among early postmenopausal and late postmenopausal women [1]. In Poland as well as in western countries sexuality is often considered the domain of the young, and the idea of older women having and enjoying sex seems to bother many people [2, 3]. It is still more acceptable for older men than older women to have sexual life. The ideas of older women's sexuality often stem from Victorian times, where the woman was passive in her sex life, and sex was mainly for reproductive purposes [4]. There is a reluctance to talk about sexual activity of mature and older women. Consequently, there is resistance of them to share about sex life, which is considered marginal issue in that age group.

Female sexual function is a complex of physiological, psychological, social, and cultural stimuli, which can affect various aspects of sexual response such as desire, arousal, lubrication, and orgasm [5]. Menopause re- quires psychological and physical adjustments because of the occurring significant hormonal changes. Sexuality is one of the aspects that undergoes the most profound modifications [6]. Early menopausal transition is marked by increased variability in menstrual cycle length, defined as a persistent difference of seven days or more in the length of consecutive cycles. The late menopausal transition is marked by the occurrence of amenorrhoea of 60 days or longer. Menstrual cycles in the late menopausal transition are characterised by increased variability in cycle length, extreme fluctuations in hormonal levels, and increased prevalence of anovulation [7-9]. The median age of menopause among Caucasian women from industrialised countries range between 50 and 52 years and at onset of the perimenopause is $47.5 \mathrm{y}$ [10]. The average age of women at the time of menopause is $51 \mathrm{y}$ in the US. The most common age range at which women experience menopause' symptoms is 48-55 y [11]. In Poland the overall median age at natural menopause is $51.25 \mathrm{y}$. Variation in age at menopause 
revealed the age range from $45 \mathrm{y}$ to $56 \mathrm{y}$ [12]. The process involves the gradual build-up of ovarian hormonal insufficiency, end of menstruation, and the end of fertile age [13]. Genitourinary syndrome of menopause (GSM) consists of a collection of symptoms and signs associated with a decrease in oestrogen and other sex steroids, involving changes to the labia majora/minora, clitoris, vestibule/introitus, vagina, urethra, and bladder. The syndrome may include genital symptoms of dryness, burning, and irritation; sexual symptoms of lack of lubrication, discomfort or pain, and impaired function; and urinary symptoms of urgency, dysuria, and recurrent urinary tract infections $[14,15]$. These changes are not synonymous with the disappearance of sexual needs. The entire early postmenopause phase lasts approximately five to eight years. During that period follicle stimulating hormone (FSH) continues to increase and estradiol continues to decrease until approximately two years after the final menstrual period, after which the levels of each of these hormones stabilise. The late postmenopause is estimated to start about eight years after the final menstrual period [16] and is represented more by changes of the somatic than reproductive systems [7, 14]. Reduced levels of oestrogens and androgen are associated with dramatic alterations in genital tissue structure, including the nerve network, as well as the response to physiological modulators. Furthermore, oestrogen and androgen deficiency is associated with reduced expression of sex steroid receptors and most importantly with attenuated genital blood flow and lubrication in response to pelvic nerve stimulation [17].

A massive and growing market for drugs and devices to treat sexual problems targets older adults, including women. There is limited information about sexual behaviours among older adults and about how sexual activities change with aging and illness [16].

The aim the study was to assess the prevalence of sexual dysfunction, behaviours, and preferences in the Polish population in 2015, as a continuation of the previous studies of Prof. Zbigniew Lew-Starowicz, which were conducted in 1992 and 2005.

\section{Material and methods}

\section{Study design}

It was an observational survey study that was conducted among 1054 people aged from 18 to over $70 \mathrm{y}$. The sample was representative for the Polish population. The study involved 538 women, of whom 220 were over 50 years old.

The survey consisted of 82 questions, grouped into the following categories:

- general questions, e.g. sex, age group, marital status, place of residence, etc.,

- early sexual contacts,
- sex life,

- relationships,

- sexual behaviours and preferences.

Due to the study design the menopausal status was defined based on the women's age, only. Therefore, for the purpose of this analysis we focused only on the female population that was stratified to the following age groups of: 35-49 y and over $50 \mathrm{y}$. The last group was stratified to the subgroups 50-59 y and over $60 \mathrm{y}$ (60-69 y, and over $70 \mathrm{y}$ ). The main focus was put on the underlying differences and changes between above age groups, mainly 50-59 y (early postmenopausal) and over 60 y (late postmenopausal).

\section{Data collection}

The data was collected via Computer Assisted Web Interviewing (CAWI) between 4 and 15 December 2015. Respondents were members of the Ariadna National Panel, which involves over 100 thousand responders and operates in accordance with the International Code of Ethics ICC/ESOMAR and the General Inspector for Personal Data Protection.

There were no dropouts and all collected data was further analysed.

\section{Statistical analysis}

All statistical analysis was performed using IBM SPSS Statistics $22 \mathrm{pl}$. The parameters used to describe quality data were the following: percentage and number of events, and to characterise quantitative data: average, median, standard deviation, minimal, and maximal values. Additionally, normality test and Kolgomorov-Smirnov statistics were performed. Statistical reasoning was based on statistical significance. It was assumed that null hypothesis was not true when $p<0.05$. Statistical reasoning was based on $95 \%$ confidentiality intervals. In order to test correlation between quality variables $\chi^{2}$ test analysis, column proportions test with Bonferroni amendment; analysis of correlation (correlation coefficient was adjusted to the data analysed), and effect size measurement were performed.

\section{Results}

Most women over 50 y lived in villages (33.6\%) and in cities of $51-500$ thousand inhabitants (28.2\%). In small and middle size cities lived $23.6 \%$ of those women. Most of them were married (57.7\%). Most widows were observed in the group over 60 y $(22.5 \%)$, and besides that there were no statistically significant differences regarding marital status among the women over $50 \mathrm{y}$. Most of them had children (90.9\%). In terms of education, $47.3 \%$ of them had secondary education and $31.4 \%$ had higher education. Most women (81.2\%) were catholic and 


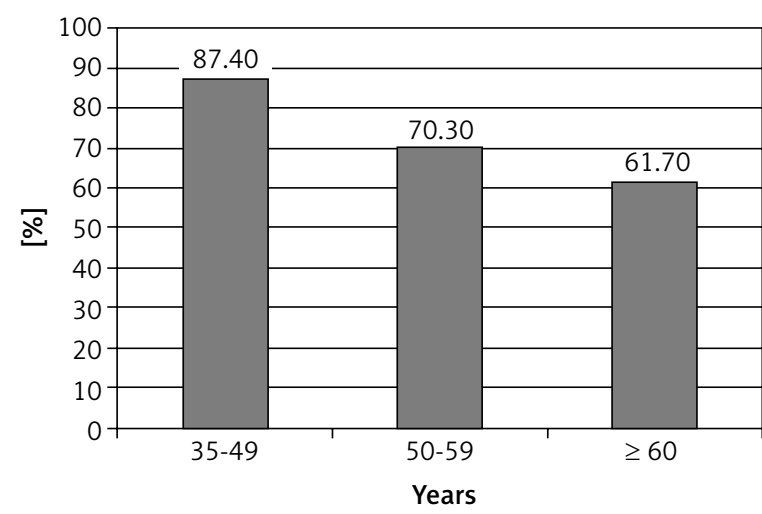

Fig. 1. Relation between age and sexual activity

$18.8 \%$ had a neutral attitude to religion or were atheists or agnostics. Over $1 / 3$ of the studied population (37.3\%) had a permanent job, $4 \%$ had a part time job, and $5.45 \%$ were unemployed.

In terms of health issues $54.1 \%$ of women over $50 \mathrm{y}$ claimed to be rather healthy, $19.5 \%$ rather ill, $14.5 \%$ healthy, and $7.3 \%$ sick or very sick. In the group of women over 60 y cardiovascular problems and osteoarticular problems were more often observed. Women in the group of 50-59 y declared problems with the endocrine system, more often than other age groups. There was no significant difference between the age groups and the prevalence of health problems, besides the fact that women aged 35-49 y were less likely to declare that they suffered from chronic diseases than other age groups and took less medication. In addition, in none of the analysed age groups disease diagnosis or taken medication caused change in their sexual life.

\section{Sexual life}

Most women over 50 y were heterosexual $82.7 \%$ (12.3\% had problems or refused the answer).

Sex played at least a moderately important role in life for $80.9 \%$ of the women above $50 \mathrm{y}$ and for $40.45 \%$ it was definitely important and very important.
Almost $2 / 3$ of women over 50 y claimed to feel sexually attractive and rather attractive (60.9\%), while $15 \%$ of them felt rather not and $5.9 \%$ definitely not attractive. There were no significant differences among the subgroups.

Most women over 50 y (65.5\%) were sexually active, but they were less active comparing to younger women $\left(\chi^{2}(2)=23.12, p<0.001\right)$. Graphically, the results are shown below (Fig. 1).

Among inactive women over $50 \mathrm{y}, 81.3 \%$ of them was inactive for over a year. There were no statistically significant differences in the subgroups.

Among women between 50 and 59 y $(n=25)$ the reasons for not being active were the following: lack of the partner (40\%), lack of interest in sex $(24 \%)$, health issues (16\%), and lack of partner's interest in sex (1.6\%). Among health issues most women had cardiovascular (22.2\%) and osteoarticular (40.7\%) problems. Endocrine system problems were reported by $14.81 \%$, urinary tract issues by $7.41 \%$, and gynaecological problems by $3.7 \%$ of them.

In the age group over $60 \mathrm{y}(n=38)$, lack of the partner (57.9\%) was the main reason for being sexually inactive. Lack of interest in sex was reported by $34.2 \%$ and lack of partner's interest in sex by $10.5 \%$ of the subgroup. Issues with health were not the important reason for being inactive and were reported only by one woman (2.6\%). In regards of health issues, sexually inactive women over 60 y reported mainly cardiovascular $(36.7 \%)$ and osteoarticular problems (36.7\%). Issues with endocrine system were reported by $6.12 \%$, gynaecological problems $6.12 \%$, and urinary tract $18.37 \%$ of the women.

Generally, $60.5 \%$ of sexually inactive women over $50 \mathrm{y}$ claimed that sex played at least a moderately significant role in their life. In addition, 39.4\% of those women were married or had a partner relationship, and $30.3 \%$ of women over $50 \mathrm{y}$ felt the desire to have sexual intercourse at least once a month. There were no significant differences among the subgroups. It could be assumed that lack of a partner was the main reason for stopping sexual activity among women over $50 \mathrm{y}$.

Tab. I. The relation between age and feeling the desire for sexual intercourse

\begin{tabular}{|c|c|c|c|c|c|}
\hline & & \multicolumn{3}{|c|}{ Age [years] } & \multirow{2}{*}{ Total } \\
\hline & & $35-49$ & $50-59$ & $\geq 60$ & \\
\hline \multirow{8}{*}{$\begin{array}{l}\text { How often do you feel desire } \\
\text { for sexual intercourse? }\end{array}$} & Several times a day & $0.7 \%^{a}$ & - & $0.9 \%^{a}$ & $0.6 \%$ \\
\hline & Every day & $8.1 \%^{a}$ & $2.4 \%{ }^{a, b}$ & $0.9 \%^{b}$ & $4.2 \%$ \\
\hline & Several times a week & $36.0 \%^{a}$ & $23.5 \%$ a,b & $21.1 \%^{b}$ & $27.8 \%$ \\
\hline & Once a week & $12.5 \%^{\mathrm{a}}$ & $15.3 \%^{\mathrm{a}}$ & $16.7 \%^{a}$ & $14.6 \%$ \\
\hline & Several times in a month & $25.7 \%^{\mathrm{a}}$ & $25.9 \%^{\mathrm{a}}$ & $26.3 \%^{a}$ & $26.0 \%$ \\
\hline & Once a month & $7.4 \%^{a}$ & $12.9 \%^{a}$ & $11.4 \%^{a}$ & $10.1 \%$ \\
\hline & Several times in a year & $3.7 \%^{a}$ & $10.6 \%{ }^{b}$ & $7.9 \% \%^{a, b}$ & $6.9 \%$ \\
\hline & I don't feel the need & $5.9 \%^{a}$ & $9.4 \%{ }^{a, b}$ & $14.9 \%$ b & $9.9 \%$ \\
\hline
\end{tabular}

a,beach letter in the index denotes the subset of the age category; the proportions of the column do not differ significantly from each other at 0.05 
Tab. II. The relation between age and frequency of intercourse

\begin{tabular}{|c|c|c|c|c|c|}
\hline & & \multicolumn{3}{|c|}{ Age [years] } & \multirow{2}{*}{ Total } \\
\hline & & $35-49$ & $50-59$ & $\geq 60$ & \\
\hline \multirow{8}{*}{$\begin{array}{l}\text { How often do you } \\
\text { have sexual } \\
\text { intercourse? }\end{array}$} & Several times a day & $1.7 \%^{\mathrm{a}}$ & - & - & $0.8 \%$ \\
\hline & Every day & $3.4 \%^{a}$ & - & - & $1.5 \%$ \\
\hline & Several times a week & $33.9 \%^{\mathrm{a}}$ & $29.7 \%^{a}$ & $22.8 \%^{\mathrm{a}}$ & $29.5 \%$ \\
\hline & Once a week & $13.6 \%^{a}$ & $21.9 \%^{a}$ & $21.5 \%^{a}$ & $18.0 \%$ \\
\hline & Several times in a month & $31.4 \%^{\mathrm{a}}$ & $32.8 \%^{a}$ & $25.3 \%^{a}$ & $29.9 \%$ \\
\hline & Once a month & $4.2 \%^{a}$ & $10.9 \%^{a}$ & $7.6 \%^{a}$ & $6.9 \%$ \\
\hline & Several times in a year & $6.8 \%^{a}$ & $3.1 \%^{\mathrm{a}}$ & $16.5 \%^{\mathrm{b}}$ & $8.8 \%$ \\
\hline & I don't know/hard to say & $5.1 \%^{a}$ & $1.6 \%^{a}$ & $6.3 \%^{a}$ & $4.6 \%$ \\
\hline
\end{tabular}

a,bEach letter in the index denotes the subset of the age category; the proportions of the column do not differ significantly from each other at 0.05

Tab. III. The relation between age and frequency of intercourse

\begin{tabular}{|c|c|c|c|c|}
\hline & & \multicolumn{2}{|c|}{ Age [years] } & \multirow{2}{*}{ Total } \\
\hline & & $60-69$ & $\geq 70$ & \\
\hline \multirow{6}{*}{$\begin{array}{l}\text { How often do you have } \\
\text { sexual intercourse? }\end{array}$} & Several times a week & $12.8 \%^{a}$ & $32.5 \%{ }^{b}$ & $22.8 \%$ \\
\hline & Once a week & $23.1 \%^{a}$ & $20.0 \%^{a}$ & $21.5 \%$ \\
\hline & Several times in a month & $33.3 \%^{a}$ & $17.5 \%^{\mathrm{a}}$ & $25.3 \%$ \\
\hline & Once a month & $7.7 \%^{a}$ & $7.5 \%^{a}$ & $7.6 \%$ \\
\hline & Several times in a year & $15.4 \%^{a}$ & $17.5 \% \mathrm{a}$ & $16.5 \%$ \\
\hline & I don't know/hard to say & $7.7 \%^{a}$ & $5.0 \%^{a}$ & $6.3 \%$ \\
\hline
\end{tabular}

${ }_{a, b}$ Each letter in the index denotes the subset of the age category; the proportions of the column do not differ significantly from each other at 0.05

Tab. IV. The relation between age and frequency of the sexual intercourse

\begin{tabular}{|c|c|c|c|c|c|}
\hline & & \multicolumn{3}{|c|}{ Age [years] } & \multirow{2}{*}{ Total } \\
\hline & & $35-49$ & $50-59$ & $\geq 60$ & \\
\hline \multirow{4}{*}{$\begin{array}{l}\text { What do you think about } \\
\text { the number of times of sexual } \\
\text { intercourse in the past } 12 \text { months? }\end{array}$} & Not enough & $31.9 \%^{a}$ & $17.6 \%{ }^{\mathrm{b}}$ & $22.7 \%$ a,b & $24.9 \%$ \\
\hline & Adequate number & $50.4 \%$ a,b & $54.9 \%^{\mathrm{b}}$ & $40.6 \%^{a}$ & $48.0 \%$ \\
\hline & Too many intercourses & $3.7 \%$ & $1.1 \%^{a, b}$ & - & $1.7 \%$ \\
\hline & I don't know/hard to say & $14.1 \%^{\mathrm{a}}$ & $26.4 \%^{b}$ & $36.7 \%$ b & $25.4 \%$ \\
\hline
\end{tabular}

a,b Each letter in the index denotes the subset of the age category; the proportions of the column do not differ significantly from each other at 0.05

Among the sexually active women, significant differences were observed regarding the desire for sexual intercourse between the subgroups $\left(\chi^{2}(14)=26.79\right.$, $p<0.05)$. Women in the group 35-49 y were more likely to feel the desire to have intercourse every day or several times a week in comparison to women aged over $50 \mathrm{y}$. In addition, women in the subgroup over $60 \mathrm{y}$ more often declared that in general they do not have such feelings (Table I). Moreover, it was observed that women over 70 y much more often declared to feel the desire for sexual intercourse several times a week (32.5\%) compared to women aged 60-70 y (12.8\%).

There were no significant differences among analysed groups in regards to the frequency of having intercourse, beside the respondents over 60 y more often than other groups declaring that sexual intercourse took place several times a year $\left(\chi^{2}(14)=25.22, p<0.05\right)$
(Table II). Regardless age, the respondents were more likely to have sexual intercourse several times in a month.

After stratification of the group over 60 y into subgroups, no relation between age and frequency of sexual intercourse was found besides women over 70 y more frequently declaring to have sexual intercourse several times a week compared to women aged 60-69 y $\left(\chi^{2}(5)=5.68, p>0.05\right)$ (Table III).

Regarding the assessment of intercourse frequency, women in the group of 50-59 y statistically less often than younger women declared that the frequency of intercourse that they had is too low. Women in groups 50-59 y and over 60 y more often than younger ones had problems with the assessment (Table IV).

No significant differences between all analysed groups were found in terms of the frequency of hav- 


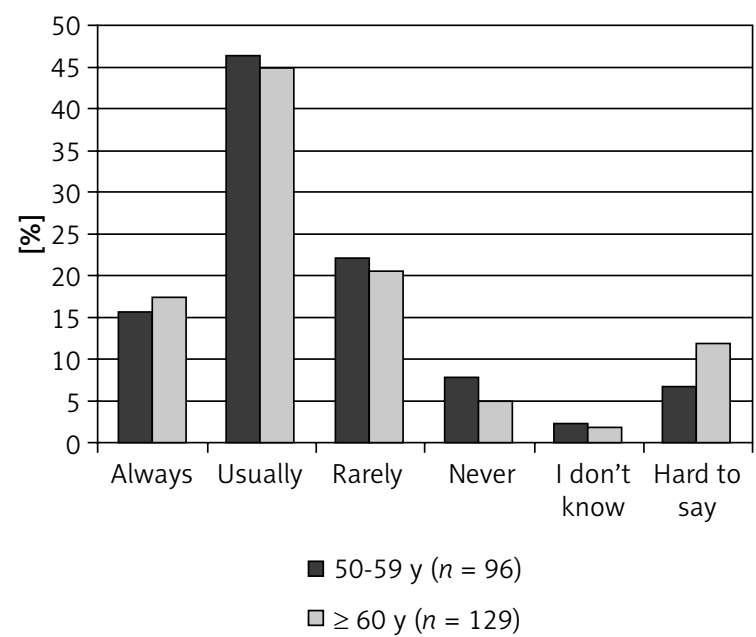

Fig. 2. The relations between age and having orgasm during sexual intercourse

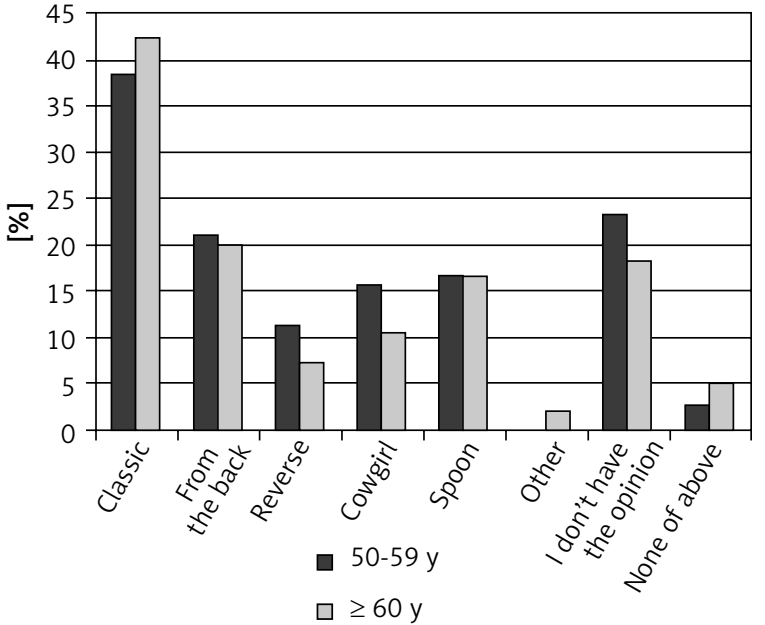

Fig. 3. The relation between age and sexual positions

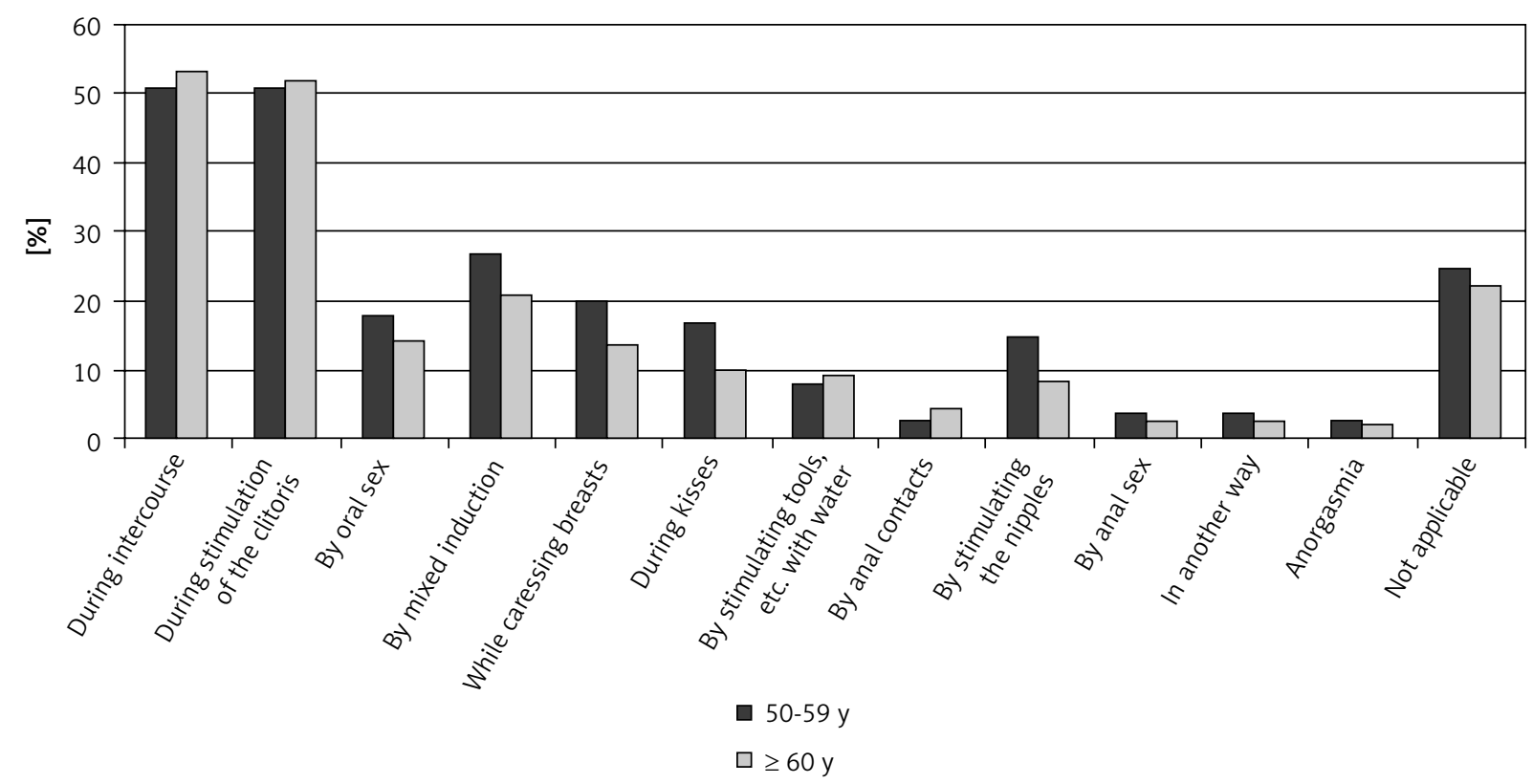

Fig. 4. The relation between age and how the women climax

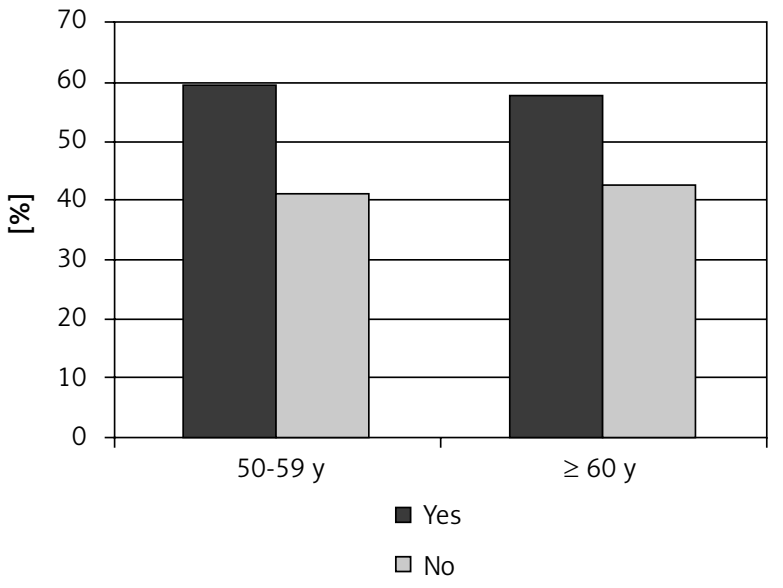

Fig. 5. Relation between age and masturbation ing orgasm as well as favourite positions during intercourse. The data regarding groups 50-59 y and over $60 \mathrm{y}$ are presented in Figures 2 and 3.

There were also no statically relevant differences regarding how the women reach orgasm among all analysed groups. The data regarding groups 50-59 y and over 60 y are presented in Figure 4.

There were also no statistically relevant differences regarding masturbation and its frequency among all analysed groups. The data regarding groups 50-59 y and over 60 y are presented in Figures 5 and 6 .

The results showed that with age, women have fewer sexual fantasies $\left(\chi^{2}(2)=12.52, p<0.01\right)$ (Table V).

However, after comparing age subgroups; 60-69 y and over $70 \mathrm{y}$, it could be observed that women over 70 y were 
significantly more likely to have sexual fantasies than women aged 60-70 y $\left(\chi^{2}(1)=4.08, p<0.05\right)$ (Table VI).

Moreover, all the age groups did not differ in terms of the content and with whom they realise the sexual fantasies. Less than half of the women over 50 y (42.7\%) realised their fantasies, $78.9 \%$ among them with their husbands and partners and $26.32 \%$ with their lovers.

Regarding use of sex tools/toys and watching pornographic movies, there were no significant differences among all the analysed groups. The data regarding groups 50-59 y and over 60 y are presented in Figures 7 and 8 . In addition, there was a trend showing that women over the age of $70 \mathrm{y}$ were much more likely to use sexual tools (15.9\%) than women aged $60-70 \mathrm{y}$ $\left(6.1 \%, \chi^{2}(1)=3.21, p=0.073\right)$.

There were no differences between the age groups women $50-59$ y and over 60 y with regard to what they find to be pleasurable. After the stratification group $60 \mathrm{y}$ into subgroups it could be observe that women over $70 \mathrm{y}$ compared to women aged 60-70 y more often indicated as pleasurable: masturbation, watching pornography, and unusual places to have sex (Table VII).

In terms of the sexual problems, there were no significant differences between the analysed groups. There was a tendency that women up to 49 y declared more sexual problems than older women. Women over $50 \mathrm{y}$ reported fewer problems, e.g. less often they claimed that sex is pleasurable $(p=0.064)$. Moreover, women over 70 y more often reported problems with climax and feeling disgust for sex and less often claimed muscular contraction that prevents intercourse or climaxing too quickly (Table VIII).

In the case of occurrence of sexual problems, women over 50 y less often than younger groups sought help $\left(\chi^{2}(2)=6.75, p<0.05\right)$. Among those who searched for help, there was no significant difference in where or how they sought the support.

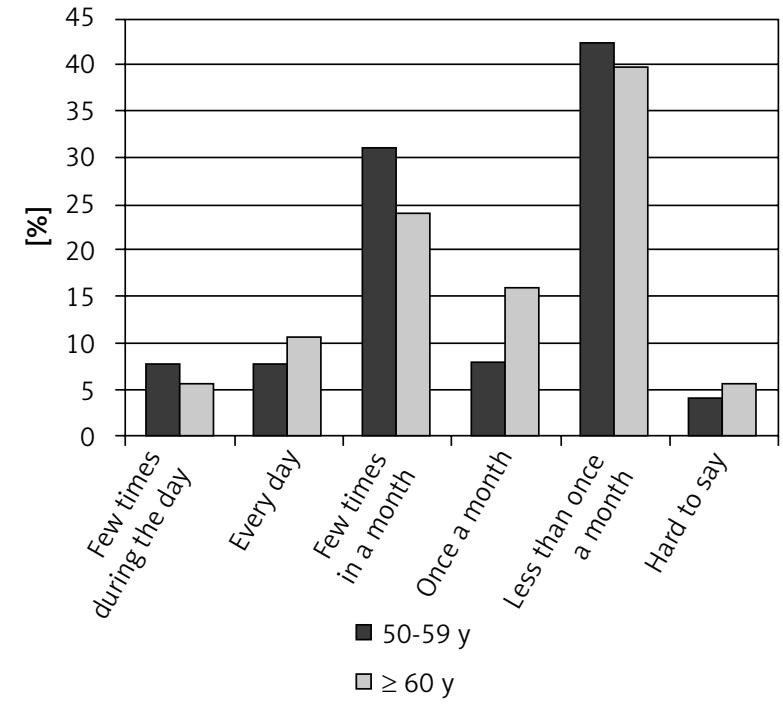

Fig. 6. Relation between age and frequency of masturbation

\section{Relationships}

Most women over 50 y reported having a partner $(70.5 \%)$. The number of women declaring to have a partner decreased with age $\left(\chi^{2}(2)=6.92, p<0.05\right)$ (Table IX). Most of the women over $50 \mathrm{y}$ had had a partner for more than five years (89.2\%).

While analysing the age groups no significant differences were found in terms of emotional and physical bond with the partner as well as in regards to assessment of the number times of sexual intercourse. The data regarding groups 50-59 y and over 60 y are presented in Figures 9-11.

No significant differences were found between the sexual intercourse outside the relationship. Compared age groups did not differ in the prevalence of such sexual contact - most (34.2\%) women over 50 y had $2-4$ sexual partners, $28.7 \%$ had one partner and $23.7 \%$ had

Tab. V. The relation between age and the occurrence of sexual fantasies

\begin{tabular}{lccccc}
\hline & & & \multicolumn{2}{c}{ Age [years] } & Total \\
\cline { 3 - 5 } & & $35-49$ & $50-59$ & $\geq 60$ & \\
\hline \multirow{2}{*}{ Do you have sexual fantasies? } & Yes & $59.3 \%^{\mathrm{a}}$ & $42.9 \%^{\mathrm{b}}$ & $38.8 \%^{\mathrm{b}}$ & $47.80 \%$ \\
\cline { 2 - 5 } & No & $40.7 \%^{\mathrm{a}}$ & $57.1 \%^{\mathrm{b}}$ & $61.2 \%^{\mathrm{b}}$ & $52.20 \%$ \\
\hline
\end{tabular}

a,b Each letter in the index denotes the subset of the age category; the proportions of the column do not differ significantly from each other at 0.05

Tab. VI. The relation between age and the occurrence of sexual fantasies

\begin{tabular}{|c|c|c|c|c|}
\hline & & \multicolumn{2}{|c|}{ Age [years] } & \multirow{2}{*}{ Total } \\
\hline & & $60-70$ & $\geq 70$ & \\
\hline \multirow{2}{*}{ Do you have sexual fantasies? } & Yes & $30.3 \%{ }^{a}$ & $47.6 \%^{\mathrm{b}}$ & $38.80 \%$ \\
\hline & No & $69.7 \%$ & $52.4 \%^{\mathrm{b}}$ & $61.20 \%$ \\
\hline
\end{tabular}

${ }_{a, b}$ Each letter in the index denotes the subset of the age category; the proportions of the column do not differ significantly from each other at 0.05 


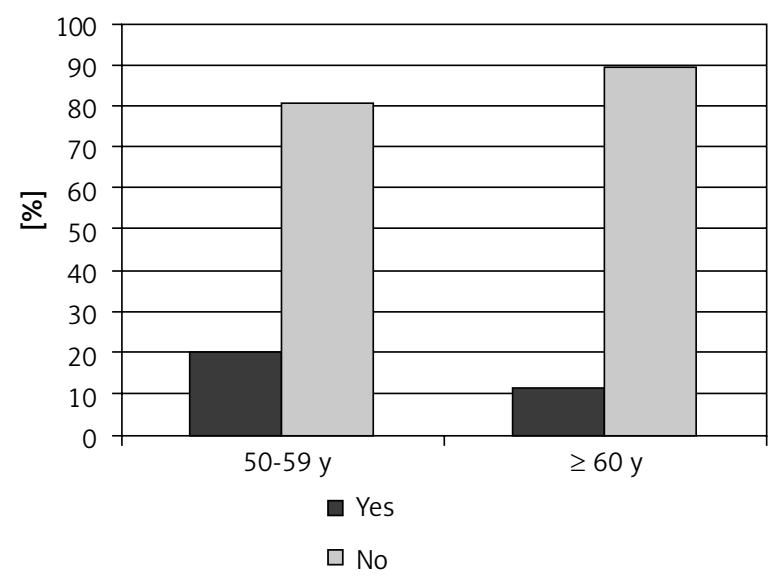

Fig. 7. Relation between age and the use of sex tools

Tab. VII. The relation between the age and what women find pleasurable

\begin{tabular}{lcc}
\hline & \multicolumn{2}{c}{ Age [years] } \\
\cline { 2 - 3 } & $60-70$ & $\geq 70$ \\
\hline Masturbation & $15.2 \%$ & $22.2 \%$ \\
\hline Pornography & $3.0 \%$ & $7.9 \%$ \\
\hline Vibrators, erectors etc. & $7.6 \%$ & $9.5 \%$ \\
\hline Oral sex & $21.2 \%$ & $25.4 \%$ \\
\hline Anal sex & $3.0 \%$ & $4.8 \%$ \\
\hline Exchange of partners & $0.0 \%$ & $1.6 \%$ \\
\hline Intercourse among three people & $1.5 \%$ & $1.6 \%$ \\
\hline Unusual sexual positions & $19.7 \%$ & $20.6 \%$ \\
\hline Unusual places to have sex & $12.1 \%$ & $25.4 \%$ \\
\hline Group sex & $1.5 \%$ & $0.0 \%$ \\
\hline
\end{tabular}

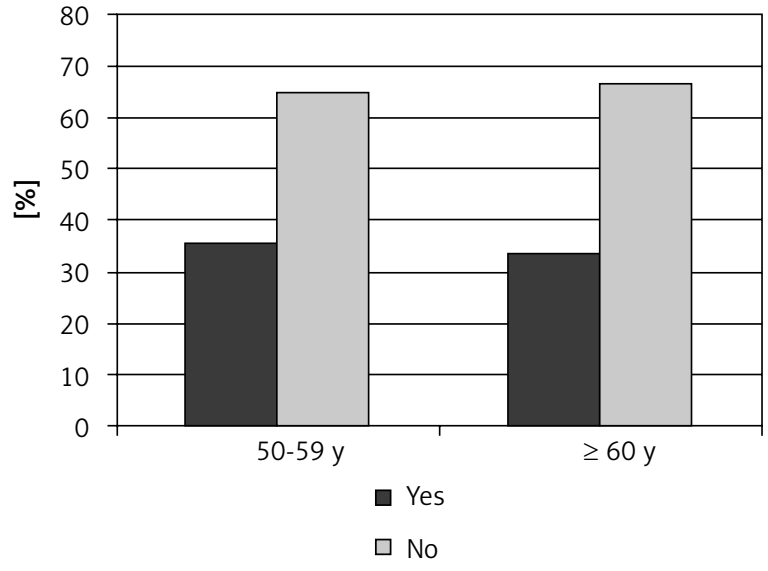

Fig. 8. Relation between age and watching pornographic movies

a regular partner outside the relationship. The data regarding groups 50-59 y and over 60 y are presented below (Fig. 12).

\section{Discussion and Conclusions}

The results of the study indicate that the majority of mature and older women are engaged in spousal or other intimate relationships and consider sexuality as an important part of life [18]. The prevalence of sexual activity declines with age, yet a substantial number of women engage in vaginal intercourse, oral sex, and masturbation, even past the seventh decade of life. In Poland $65.5 \%$ of women above 50 y and $61.5 \%$ above 60 y were sexually active. Regardless of age, the respondents were more likely to have sexual intercourse several times in

Tab. VIII. The relation between age and reported sexual problems

\begin{tabular}{|c|c|c|c|}
\hline Problems declared by a respondent & $50-59$ y & $60-70 y$ & $\geq 70 y$ \\
\hline Reduced sexual needs/lack of interest in sex & $31.25 \%$ & $33.30 \%$ & $37.50 \%$ \\
\hline Rarely climaxing & $18.75 \%$ & $17.90 \%$ & $27.50 \%$ \\
\hline Pain during intercourse & $12.50 \%$ & $15.40 \%$ & $15.00 \%$ \\
\hline Difficulty with lubrication & $18.75 \%$ & $17.90 \%$ & $20.00 \%$ \\
\hline Anorgasmia & $12.50 \%$ & $17.90 \%$ & $12.50 \%$ \\
\hline Sex not pleasurable & $7.81 \%$ & $5.10 \%$ & $7.50 \%$ \\
\hline Climaxing too quickly & $7.81 \%$ & $5.10 \%$ & $5.00 \%$ \\
\hline Feeling disgust for their partner & $3.13 \%$ & $2.60 \%$ & $2.50 \%$ \\
\hline Feeling disgust for sex & $3.13 \%$ & $0.00 \%$ & $5.00 \%$ \\
\hline Muscular contraction that prevents intercourse & $3.13 \%$ & $5.10 \%$ & $0.00 \%$ \\
\hline Feeling disgust for men / women & $3.13 \%$ & $0.00 \%$ & $0.00 \%$ \\
\hline Excessive sexual needs & $0.00 \%$ & $5.10 \%$ & $2.50 \%$ \\
\hline
\end{tabular}

Tab. IX. The relation between age and having regular partner

\begin{tabular}{|c|c|c|c|c|c|}
\hline & & \multicolumn{3}{|c|}{ Age [years] } & \multirow{2}{*}{ Total } \\
\hline & & $35-49$ & $50-59$ & $\geq 60$ & \\
\hline \multirow{2}{*}{ Do you have a partner? } & Yes & $86.4 \%^{a}$ & $79.1 \% \%^{a, b}$ & $73.6 \%^{b}$ & $80.00 \%$ \\
\hline & No & $13.6 \%^{a}$ & $20.9 \% \%^{a, b}$ & $26.4 \%^{b}$ & $20.00 \%$ \\
\hline
\end{tabular}

a,bach letter in the index denotes the subset of the age category; the proportions of the column do not differ significantly from each other at 0.05 


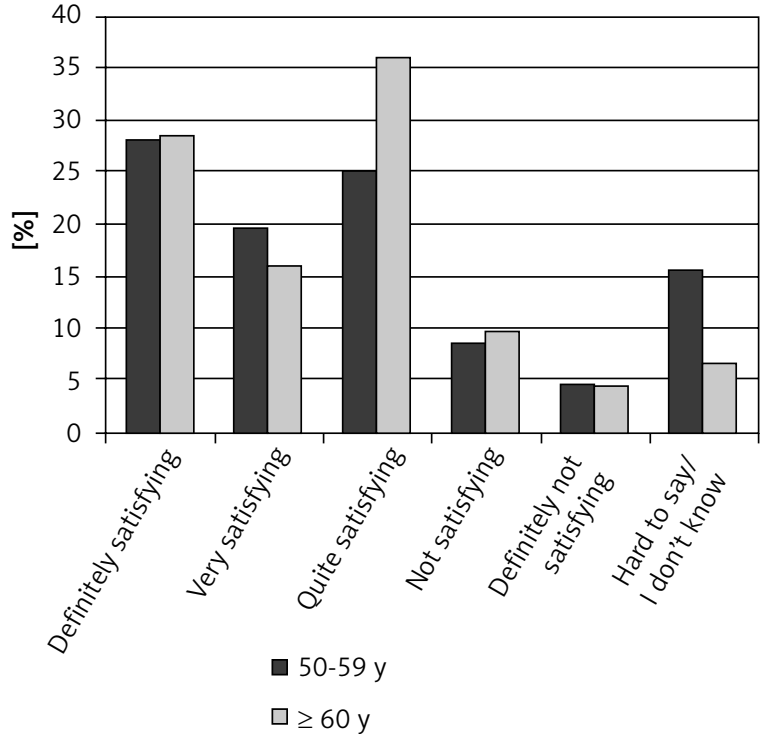

Fig. 9. Relation between age and emotional contact with the partner

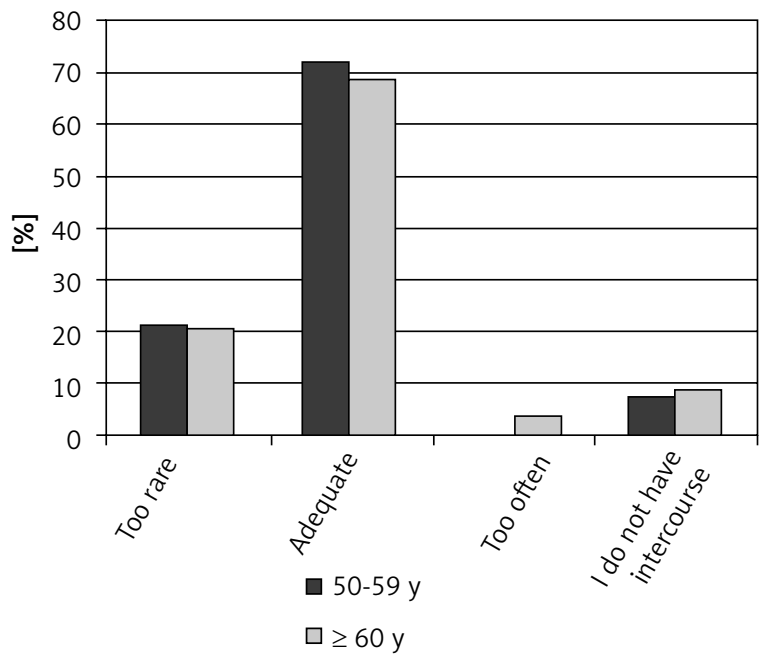

Fig. 11. Relation between age and frequency of intercourse

a month. Women in groups 35-49 y and 50-59 y had sexual intercourse more often several times a week $(33.9 \%$ and $29.7 \%$, respectively) comparing to women above 60 y (22.8\%). Though women above 60 y reported to have sexual intercourse once a week more often comparing to younger women $35-49$ y (21.5\% vs. $13.6 \%)$. In both age groups, 50-59 y and over $60 \mathrm{y}$, the main reason for being sexually inactive was the lack of a partner: $40 \%$ and $57.9 \%$, respectively. Health issues were more often reported as a reason for being sexually inactive in the group $50-59$ y (16\%) than in over 60 y (2.6\%), probably due to adapting to menopausal status, which is associated with changes in vaginal physiology, thus contributing changes in sexual function [19]. Moreover, the mature and older women claimed that health problems and medicines they had been taking did not have an impact on their sexual life. In addition, the preva-

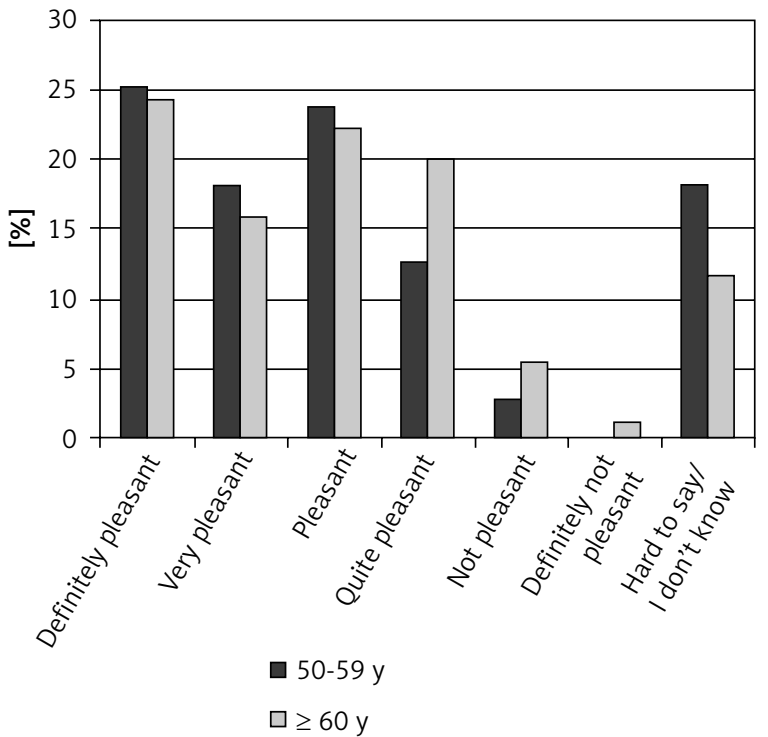

Fig. 10. Relation between age and sexual contact with the partner

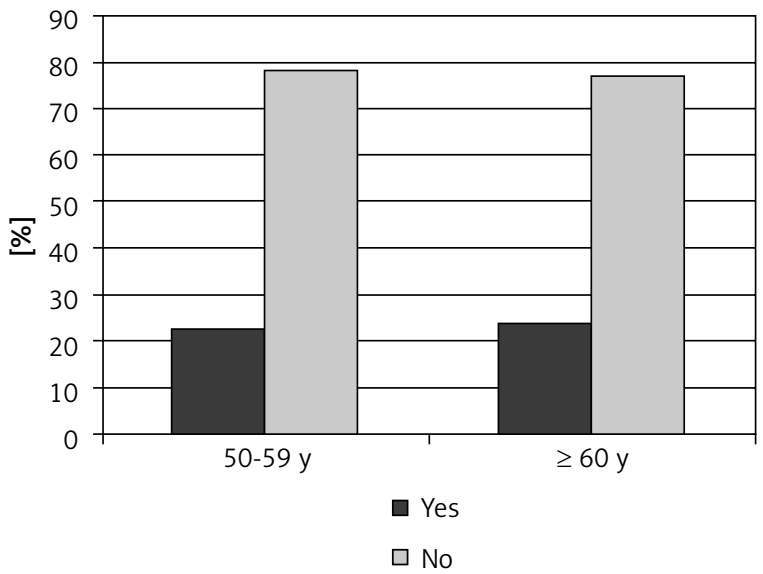

Fig. 12. Relation between age and occurrence of Intercourse outside the relationship

lence of sexual problems was not higher in age groups 50-59 y and 60 y comparing to younger women. Women over 50 y reported fewer problems in comparison to younger women, e.g. less often they claimed that sex is not pleasurable $(p=0.064)$. The often-reported problems were lack of lubrication (20\%) and decreased or lack of sexual need, but the prevalence was similar in all analysed groups. Moreover, women over 70 y more often reported problems with climaxing and feeling disgust for sex. They less often claimed muscular contraction that prevents intercourse or climaxing too quickly. The disturbing fact is that, with age, women do not seek help from professionals. They might fear there is a lack of social acceptance of discussing the healthy possibilities and experience of sexual behaviour [20].

The study had some limitations - only women using the Internet were involved. It would be difficult to obtain the data, due to the number of questions and the 
fact that people remain silent about their problems. As with most sexuality research, an additional limitation of our study is the fact that the data were self-reported, although the interview methods are well accepted as being valid. Moreover, we assessed only specific sexual problems and asked general questions about health problems, as it was a population based study. Therefore, our findings are likely to underestimate the extent of sexual problems in the older female population. Prospective, longitudinal data are needed to better understand the associations between sexual problems and future sexual activity or relationships.

Our findings are promising, showing that mature and older women are open-minded, confident, and can enjoy sexual life. It could be concluded with the following from J. Krzyżowski: "Although the frequency of sexual activity in older age is lower and decreases with age, the desire for sex and the desire to rejoice is not always lower" [21].

\section{Acknowledgements}

The project was supported by Polpharma SA and by Zymetria Sp. z o.o., which was responsible for the data collection.

\section{Disclosure}

Authors report no conflict of interest.

\section{References}

1. Salonia A, Giraldi A, Chivers ML, et al. Physiology of women's sexual function: basic knowledge and new findings. J Sex Med 2010; 7: 2637-2660.

2. Stankowska I. Funkcjonowanie seksualne człowieka w okresie starzenia się i starości. Przegląd Terapeutyczny 2008; 4.

3. Fabiś A, Fabiś A. Tabu seksuologii. Wydawnictwo Academica Szkoły Wyższej Psychologii Społecznej, Warszawa 2008.

4. Gott M. Sexuality, sexual health and aging. Open University Press, Maidenhead 2005.

5. Baldassarre M, Alvisi S, Berra M, et al. Changes in vaginal physiology of menopausal women with type 2 diabetes. J Sex Med 2015; 12: 1346-1355.

6. Berra M, De Musso F, Matteucci C, et al. The impairment of sexual function is less distressing for menopausal than for premenopausal women. J Sex Med 2010; 7: 1209-1215.

7. Harlow SD, Gass M, Hall JE, et al. Executive summary of the Stages of Reproductive Aging Workshop +10: addressing the unfinished agenda of staging reproductive aging. Menopause 2012; 19: 387-395.

8. Su HI, Freeman EW. Hormone changes associated with the menopausal transition. Minerva Ginecol 2009; 61: 483-489.

9. Harlow SD, Paramsothy P. Menstruation and the menopause transition. Obstet Gynecol Clin North Am 2011; 38: 595-607.

10. Gold EB. The timing of the age at which natural menopause occurs. Obstet Gynecol Clin North Am 2011; 38: 425-440.

11. Hormones and Menopause, National Institute on Aging, 2012, https:// www.nia.nih.gov/health/publication/hormones-and-menopause

12. Kaczmarek $M$. The timing of natural menopause in Poland and associated factors. Maturitas 2007; 57: 139-153.

13. Szwed A. Biologiczne i kulturowe uwarunkowania klimakterium u kobiet. Monografie Instytutu Antropologii UAM, Poznań 2001.

14. Portman DJ, Gass ML. Genitourinary syndrome of menopause: new terminology for vulvovaginal atrophy from the International Society for the
Study of Women's Sexual Health and the North American Menopause Society. J Sex Med 2014; 11: 2865-2872.

15. Stuart-Hamilton I. Psychologia starzenia się. Wydawnictwo Zysk i S-ka, Poznań 2000.

16. Lonnèe-Hoffmann RA, Dennerstein L, Lehert P, Szoeke C. Sexual function in the late postmenopausase: a decade of follow-up in a populationbased cohort of Australian women. J Sex Med 2014; 11: 2029-2038.

17. Traish AM, Botchevar E, Kim NN. Biochemical factors modulating female genital sexual arousal physiology. J Sex Med 2010; 7: 2925-2946.

18. Lindau ST, Schumm LP, Laumann EO, et al. Study of sexuality and health among older adults in the United States. N Engl J Med 2007; 357: 762-774.

19. Olejnik M. Średnia dorosłość. Wiek średni. Psychologia rozwoju człowieka. Rozwój funkcji psychicznych. Tom 3. PWN, Warszawa 2006.

20. Levine SB. Sexuality in mid-life. Plenum Press, New York 1998.

21. Krzyżowski J. Psychogeriatria. Wyd. Medyk, Warszawa 2004. 